\title{
INVENTORY MANAGEMENT THROUGH EXTENDED STAR-RING SUPPLY CHAIN NETWORK
}

\author{
ARUN PRASATH GM* \\ Department of Mathematics, SAS, VIT University Chennai Campus, Chennai, Tamil Nadu, India. Email: arunprasathgm@gmail.com \\ Received: 19 January 2017, Revised and Accepted: 20 February 2017
}

\section{ABSTRACT}

Objectives: The production-distribution inventory problem has two main sectors namely production and distribution. In this paper, the nonlinear mathematical model of extended star-ring supply chain network is developed.

Methods: Planning a distribution network plays a vital role in minimizing the total expenditure of the project; to prove this, a ring network topology is taken to supply goods to the SWs and extended star network topology to supply goods to the selling stores. However, setting up separate SWs for each and every selling store will be highly expensive. Hence, keeping the minimum number of SWs is very important. Selection of SWs from the available SWs is done by replacing diverse values based on the distance limitation.

Results: The suggested model is validated with the mathematical problem, and the optimum set of SWs is identified from the result. The result has been substantiated using analytic hierarchy process.

Conclusion: The system of optimum number of SWs is obtained from the result.

Keywords: Inventory model, Facility location model, Secondary warehouse, Analytic hierarchy process.

(C) 2017 The Authors. Published by Innovare Academic Sciences Pvt Ltd. This is an open access article under the CC BY license (http://creativecommons. org/licenses/by/4. 0/) DOI: http://dx.doi.org/10.22159/ajpcr.2017.v10s1.19637

\section{INTRODUCTION}

The operative choice of secondary warehouses (SWs) is the key factor for the achievement of supply chain networks $[1,3]$. The curiosity in estimating the role of supply network in previous shows the requirement for the progress of complex optimization models capable of replying unanswered questions in the manufacture supply network. Implementations of a supply chain system have decisive effects on organization's economic routine. The general act of a supply network is affected meaningfully by the decisions taken in its manufacturesupply plan integrating the decisions in production, transport, and warehousing as well as inventory management. Thus, one main problem in the act valuation of supply networks is the formulating and optimization of manufacture-supply plan considering its actual difficulty. By placing the system of SWs for filling the necessities of all SSs, the total expenses will be reduced [4].

Based on the combination of the production plan and distribution plan, a nonlinear mathematical model of extended star-ring supply chain network is established. A production-distribution inventory model with possible constraints is developed for the optimization of lot size, unit cost, shortage level, percentage of utilization of warehouse space, and the number of SWs [6,7]. In multicriteria decision-making problem, to substantiate the best decision, analytic hierarchy process (AHP) can be used. In the numerical example, substituting different values for the distance parameter will give some different optimum results. Hence, to substantiate the best optimum result, AHP [8] is used.

\section{METHODS}

\section{Mathematical model}

The proposed mathematical model is developed under the following assumptions and notations.

\section{A. Notations}

$n$ - Number of items

$\mathrm{C}_{\mathrm{i}}$ - Scaling constant

$S_{i}$ - Setup cost of the cycle

$\mathrm{t}$ - Number of orders per cycle

$\mathrm{H}_{\mathrm{u}}$ - Holding cost

$\mathrm{v}_{\mathrm{i}}$ - Volume of unit item

$\mathrm{V}$ - Volume of storage space

$\delta_{\mathrm{i}}$ - Shortage cost

I - Total investment cost of production

$\alpha$ - Number of SSs

$\beta$ - Number of planned SWs

$\mathrm{m}$ - Number of production plant

d - Maximum allowed distance between SWs and selling stores

$t_{\text {ikj - }}$ Transporting cost of the unit item between SW $k$ and SS j

$t_{\text {i } \gamma \mathrm{k}}$ - Transporting cost of the unit item between production plant $\gamma$ and SW k

$\mathrm{p}_{\mathrm{i} .}$ Unit price of the item

$\mu_{\mathrm{pi}}$ - Membership value of the unit price of the item

$Q_{\text {. Lot size }}$

$M_{i}$ Shortage level

$\mathrm{V}_{\mathrm{w}}$. Utilization percentage of storage in the SS

$S_{\text {ck }}$ Setup cost of SW k

$\mathrm{A}_{\mathrm{jk}-\mathrm{D}}$. Distance from SWs to SSs

$\mathrm{c}_{\mathrm{lm} \text {. }}$ Distance between SWs.

\section{B. Assumptions}

i. The replenishment is infinite

ii. The backorders are allowed

iii. Producing quantity is taken as a required goods for the SS from the SW

iv. Unit price is taken as triangular fuzzy number

v. Demand is taken as $D_{i}=\frac{C_{i}}{p_{i} e_{i}}[2,5]$. 
C. Objective Function

$$
\begin{aligned}
& \operatorname{Min} Z=\left\{\alpha \sum_{i=1}^{n}\left[C_{i} \tilde{p}_{i}^{1-e_{i}}+\frac{C_{i} S_{i}}{\tilde{p}_{i}{ }_{i} Q_{i}}+\frac{H_{i}\left(Q_{i}-M_{i}\right)^{2}}{2 Q_{i}}+\frac{\delta_{i} M_{i}^{2}}{2 Q_{i}}\right]+\right. \\
& \sum_{i=1}^{n} \sum_{j=1}^{\alpha} \sum_{k=1}^{\beta}\left(A_{j k} \times Q_{i} \times x_{i j k} \times t_{i k j}\right)+\sum_{k=1}^{\beta}\left(S_{c_{k}} \times y_{k}\right)+ \\
& \left.\sum_{i=1}^{n} \sum_{\gamma=1}^{m} \sum_{k=1}^{\beta}\left(y_{k} \times t_{i \gamma k} \times Q_{i}\right)+\sum_{l=1}^{\beta} \sum_{m=1}^{\beta} c_{l m} u_{l m}\right\}
\end{aligned}
$$

D. Constraints
i. Warehouse space limitation, $\sum_{\mathrm{i}=1}^{\mathrm{n}} \mathrm{v}_{\mathrm{i}} \mathrm{Q}_{\mathrm{i}} \leq \mathrm{V}$

ii. Budget limitation, $\sum_{\mathrm{i}=1}^{\mathrm{n}} \tilde{\mathrm{p}}_{\mathrm{i}} \mathrm{Q}_{\mathrm{i}} \leq \mathrm{I}$

iii. Number of orders per cycle, $\sum_{\mathrm{i}=1}^{\mathrm{n}} \frac{\mathrm{C}_{\mathrm{i}}}{\tilde{\mathrm{p}}_{\mathrm{i}} \mathrm{e}_{\mathrm{Q}} \mathrm{Q}_{\mathrm{i}}} \leq \mathrm{t}$

iv. Restriction on number of SWs assigned, $\sum_{k=1}^{\beta} y_{k} \leq \varepsilon$

v. Restriction on SS is served by exactly one SW,

$$
\sum_{i=1}^{n} \sum_{k=1}^{\beta} x_{i j k}=1, \mathrm{j}=1,2,3, \ldots, \alpha .
$$

For the constraints vi-viii the value of $k=1,2,3, \ldots, \beta$,

vi. Restriction on SS to be served by at least one SW, $\sum_{\mathrm{i}=1}^{\mathrm{n}} \sum_{\mathrm{j}=1}^{\alpha} \mathrm{x}_{\mathrm{ijk}}-\mathrm{y}_{\mathrm{k}} \geq 0$ vii. Restriction on noSS is served by unassigned SW, $\sum_{\mathrm{i}=1}^{\mathrm{n}} \sum_{\mathrm{j}=1}^{\alpha} \mathrm{x}_{\mathrm{ijk}}-\alpha \mathrm{y}_{\mathrm{k}} \leq 0$ viii. Restriction on distance from SW to SS, $\sum_{\mathrm{i}=1}^{\mathrm{n}} \sum_{\mathrm{j}=1}^{\alpha} \mathrm{A}_{\mathrm{jk}} \mathrm{x}_{\mathrm{ijk}} \leq \mathrm{d}$

ix. Stipulate that only one city can be visited from city 1 and that only one city visited at each stage of travel, $\sum_{\mathrm{l}=1}^{\beta} \mathrm{u}_{\mathrm{lm}}=1, \mathrm{~m}=1,2,3, \ldots, \beta$

x. Ensures that a given city is visited exactly one stage of travel,

$$
\sum_{\mathrm{m}=1}^{\beta} \mathrm{u}_{\mathrm{lm}}=1, \mathrm{l}=1,2,3, \ldots, \beta
$$

Restriction given in (vi) will not execute when the restriction given in (vii) is executing. Likewise, restriction given in (vii) will not execute when the restriction given in (vi) is executing.

Where $_{\mathrm{x}_{\mathrm{ijk}}}=\left\{\begin{array}{l}1, \text { if a SW } \mathrm{k} \text { is assigned to SS } \mathrm{j} \text { for unit item } \mathrm{i} \\ 0, \text { otherwise }\end{array}\right.$

$\mathrm{y}_{\mathrm{k}}=\left\{\begin{array}{l}1, \text { if a SW } \mathrm{k} \text { is assigned } \\ 0, \text { otherwise }\end{array}, \mathrm{u}_{\mathrm{lm}}=\left\{\begin{array}{l}1, \text { if there is a path from } \mathrm{l} \text { to } \mathrm{m} \\ 0, \text { otherwise }\end{array}\right.\right.$

and $\tilde{p}_{\mathrm{i}} \geq 0$ and $\mathrm{Q}_{\mathrm{i}}{ }^{3} 0(\mathrm{i}=1,2,3, \ldots, \mathrm{n})$ and $0<\mathrm{V}_{\mathrm{W}} \leq 100$. Unit cost taken as a triangular fuzzy number. The pictorial representation of the proposed configuration of supply network is presented in Fig. 1.

\section{RESULTS}

A manufacturing company has single production plant $(\mathrm{m}=1)$ produces single item $(i=1)$. The company has five selling stores $(\alpha=5)$ and five proposed SWs $(\beta=5)$. The company decided to select the system of optimum number of SWs to satisfy the supplies of the SSs which are available in various main marketplaces. The volume of the unit item and the storage space available in the SS are given by $v_{1}=8 \mathrm{~m}^{3}$ and $\mathrm{V}=3600 \mathrm{~m}^{3}$, respectively. The holding cost, setup cost, and shortage cost of the item are given by $\$ 1, \$ 100$, and $\$ 3$, respectively. Total investment cost for production is $I=\$ 1400$, and number of orders per cycle is 4 . The unit cost of the item is $\tilde{p}_{1}=\$(10,15,20)$. Maximum allowed distance between the SWs and selling stores is $d=12 \mathrm{~km}$. The unit transporting cost of single item 1 from production plant $\gamma$ to SWs $\mathrm{k}$ is given by $\mathrm{t}_{1 \gamma \mathrm{k}}=\$ 2$ and the unit transporting cost of single item 1 from $S W k$ to SS $j$ is given by $t_{1 k \mathrm{j}}=\$ 2$. The scaling constant value for the unit item 1 is $C_{1}=113$. The setup cost of SWs and the distance between the selling stores and the SWs are given in Table 1. The distances among the SWs are given in Table 2 .

The values of $\mathrm{e}_{1}$ lie between 0 and 1 . The most suitable values of $\mathrm{e}_{1}$ for the given example are obtained by trial and error method. The above suitable values of $\mathrm{e}_{1}$ are said to be selected values of $\mathrm{e}_{1}$. Only the selected values of $\mathrm{e}_{1}$ are substituted in the problem for obtaining the optimum result. Hence, the optimum values of the decision variables and the respective total expenditures are available in Table 3.

From Table 2, it is observed that for diverse values of the distance d, the diverse optimum result is obtained. To find out the best optimum result among the available optimum results, the AHP can be used. The AHP-based output is given in Table 4.

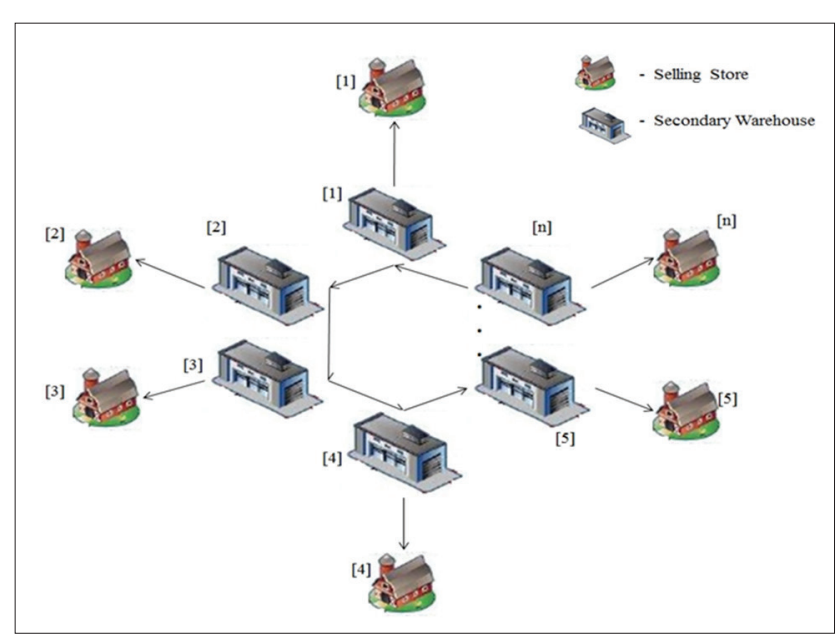

Fig. 1: Pictorial representation of the supply network

Table 1: Distance matrix $\left(A_{j k}\right)$ in $\mathrm{km}$

\begin{tabular}{lllllll}
\hline Store $(\mathbf{j})$ & \multicolumn{6}{c}{ Proposed secondary } \\
\hline & & 1 & 2 & 3 & 4 & 5 \\
& 1 & 5 & 3 & 7 & 6 & 8 \\
& 2 & 3 & 8 & 10 & 9 & 6 \\
& 3 & 10 & 9 & 6 & 3 & 9 \\
& 4 & 4 & 7 & 3 & 8 & 10 \\
Setup cost $\left(\mathrm{S}_{\mathrm{ck}}\right)$ & 5 & 9 & 8 & 10 & 9 & 3 \\
\hline
\end{tabular}

Table 2: Distance matrix $\left(\mathrm{c}_{\mathrm{lm}}\right)$ in $\mathrm{km}$

\begin{tabular}{llllll}
\hline & $\mathbf{1}$ & $\mathbf{2}$ & $\mathbf{3}$ & $\mathbf{4}$ & $\mathbf{5}$ \\
\hline 1 & 0 & 93 & 110 & 121 & 3 \\
2 & 93 & 0 & 237 & 160 & 152 \\
3 & 110 & 237 & 0 & 131 & 86 \\
4 & 121 & 160 & 131 & 0 & 97 \\
5 & 23 & 152 & 86 & 97 & 0 \\
\hline
\end{tabular}


Table 3: Output of the example ( for $d=3-6 \mathrm{~km}, \mathrm{~d}=7-8 \mathrm{~km}, \mathrm{~d}=9-11 \mathrm{~km}$ and $\mathrm{d} \geq 12 \mathrm{~km}$ )

\begin{tabular}{|c|c|c|c|c|}
\hline $\mathbf{e}_{1}$ & $\mathbf{p}_{1}$ & $\mathbf{Q}_{1}$ & $\mathbf{M}_{1}$ & $\mathbf{Z}$ \\
\hline $0.640,0.640,0.640,0.640$ & $10,10,10,10$ & $18,18,16,17$ & $4.4,4.4,4.1,4.2$ & $3880,3770,3717,3684$ \\
\hline $0.650,0.650,0.650,0.6457$ & $11,11,11,11$ & $17,17,16,17$ & $4.2,4.2,3.9,4.1$ & $3831,3722,3667,3656$ \\
\hline $0.665,0.665,0.655,0.660$ & $12,12,12,12$ & $16,16,14,16$ & $4.0,4 \cdot 0,3 \cdot 6,3.9$ & $3758,3648,3641,3585$ \\
\hline $0.670,0.670,0.665,0.668$ & $13,13,13,13$ & $16,16,14,15$ & $3.9,3.9,3.6,3.8$ & $3733,3623,3589,3544$ \\
\hline $0.680,0.680,0.670,0.6698$ & $14,14,14,14$ & $15,15,14,15$ & $3.7,3.7,3 \cdot 5,3.8$ & $3682,3572,3561,3464$ \\
\hline $0.690,0.690,0.680,0.6699$ & $15,15,15,15$ & $14,14,13,13$ & $3.6,3 \cdot 6,3 \cdot 4,3 \cdot 2$ & $3629,3519,3507,3502$ \\
\hline $0.695,0.695,0.685,0.670$ & $16,16,16,16$ & $14,14,13,13$ & $3 \cdot 5,3 \cdot 5,3 \cdot 1,3 \cdot 2$ & $3603,3493,3422,3421$ \\
\hline $0.705,0.705,0.695,0.690$ & $18,18,18,18$ & $13,13,13,12$ & $3.3,3.3,3.1,2.9$ & $3549,3439,3422,3404$ \\
\hline $0.715,0.715,0.700,0.693$ & $19,19,19,19$ & $13,13,12,12$ & $3.2,3.2,3.1,2.9$ & $3001,2891,2393,2386$ \\
\hline
\end{tabular}

Table 4: Decision matrix and solution when the AHP is used

\begin{tabular}{llll}
\hline Alternatives & \multicolumn{2}{l}{ Criterion } & Final priority \\
\cline { 2 - 4 } & Unit cost (0.2305) & Ordering quantity (0.1074) & Total cost (0.6621) \\
\hline$d=3-6 \mathrm{~km}$ & 0.2988 & 0.0555 & 0.0583 \\
$\mathrm{~d}=7-8 \mathrm{~km}$ & 0.4916 & 0.1232 & 0.1147 \\
$\mathrm{~d}=9-11 \mathrm{~km}$ & 0.0521 & 0.2427 & 0.3052 \\
$\mathrm{~d}=\geq 12 \mathrm{~km}$ & 0.1575 & 0.5787 & 0.2025 \\
\hline
\end{tabular}

AHP: Analytic hierarchy process

\section{DISCUSSION}

Therefore, from Table 4, it is observed that the best distance among the optimum distances is $d \geq 12 \mathrm{~km}$ followed by the distance $d=9-11 \mathrm{~km}$ is followed by the distance $\mathrm{d}=7-8 \mathrm{~km}$ which is followed by the distance $\mathrm{d}=3$ to $6 \mathrm{~km}$.

\section{CONCLUSION}

Using extended star-ring supply chain network, the system of optimum number of SWs is obtained to satisfy the requirements of all the selling stores. In future, some other variables can be taken as a fuzzy variable.

\section{REFERENCES}

1. Verma A, Verma R, Mahanti NC. A new approach to fuzzy uncapacitated facility location problem. Int J Soft Comput 2010;5(3):149-54.
2. Panda D, Kar S. Multi-item stochastic and fuzzy-stochastic inventory models under imprecise goal and chance constraints. Adv Model Optim 2005;7:155-67.

3. Fahimnia B, Luong L, Marian R. An integrated model for the optimization of a two-echelon supply network. J Achiev Mater Manuf Eng 2008;31(2):477-84.

4. Chung KJ, Her CC, Lin SD. A two warehouse inventory model with imperfect quality production processes. Comput Ind Eng 2009;56:193-7.

5. Mandal NK. Geometric programming approach to an interactive fuzzy inventory model. Adv Oper Res 2011;2011:1-17.

6. Panneerselvam R. Production and Operations Management: India: Prentice-Hall of India; 2010. p. 120-3.

7. Saha S, Das S, Basu M. Supply chain coordination under stock-and price-dependent selling rates under declining market. Adv Oper Res 2012:2012:1-14

8. Saaty TL. How to make a decision: The analytic hierarchy process. Eur J Oper Res 1990;48:9-26. 